\title{
Predicting latent classes of drug-related problems among adolescents: secondary analysis of a cluster randomized controlled trial
}

\author{
Mireille C. Almeida, ${ }^{1}$ (iD Juliana Y. Valente, ${ }^{2}$ (iD Zila M. Sanchez ${ }^{2}$ iD \\ ${ }^{1}$ Departamento de Psiquiatria, Universidade Federal de São Paulo (UNIFESP), São Paulo, SP, Brazil. ${ }^{2}$ Departamento de Medicina Preventiva, \\ UNIFESP, São Paulo, SP, Brazil.
}

\begin{abstract}
Objective: To detect latent patterns of drug-related problems and their predictors among adolescents. Methods: A three-wave randomized controlled trial was conducted among 6,391 7th and 8th graders (51.02\% girls) at 72 public schools in six Brazilian cities to evaluate the \#Tamojunto school-based drug prevention program. Patterns of drug use and behavior problems were identified through latent class analysis, and logistic regression analyses were used to detect predictors of high-risk and low-risk groups.

Results: Two groups were found that best explained the patterns of drug use and problem behaviors: high drug use/high problems and low drug use/low problems, representing 36.7 and $63.3 \%$ of the sample, respectively. No program effect was a determinant of the risk of belonging to these groups. Any reported problem behavior in the year preceding baseline assessment increased the likelihood of belonging to the high-risk group at the 21 -month follow-up by 16 times. Alcohol use at baseline and female gender increased the likelihood of belonging to the high-risk group by $70 \%$.

Conclusion: Previous behavior problems and alcohol use were the strongest predictors of higher risk, suggesting that effective earlier interventions and early screening for alcohol use and behavioral problems are needed at schools, particularly for girls.

Clinical trial registration: Registro Brasileiro de Ensaios Clínicos (REBEC), RBR-4mnv5g
\end{abstract}

Keywords: Adolescent; drug use; behavior problem; latent class analysis; prevention

\section{Introduction}

Adolescence is a delicate phase of transition between childhood and adulthood in which young people rebuild their inner universe and recreate their relationship with the external world. ${ }^{1}$ In an attempt to adjust themselves to their new reality and organize very intense feelings, adolescents usually manifest behaviors such as rebellion, isolation, and inconstancy. ${ }^{2}$ Therefore, adolescence is also a period of great risk for the emergence of behavioral problems ${ }^{3}$ and for the initiation of alcohol and drug use. ${ }^{4}$

Among Brazilian students aged 13 to 15 years, the reported lifetime prevalence of alcohol consumption is $55.5 \%$, and that of illicit drug use is $9.0 \%{ }^{5}$ This early onset of drug use has several potential negative consequences, such as health risks (accidents, homicide, and suicide), problematic sexual behaviors, school dropout, and involvement in episodes of violence, including theft, vandalism, drug-related crimes, and assault. ${ }^{6}$

Due to the public health impact of drug-related problems in adolescence, it is important to identify the

Correspondence: Zila M. Sanchez, Departamento de Medicina Preventiva, Universidade Federal de São Paulo, Rua Botucatu, 740, sala 404, CEP 04023-062, São Paulo, SP, Brazil.

E-mail: zila.sanchez@ unifesp.br

Submitted Apr 26 2020, accepted Aug 05 2020, Epub Nov 232020. predictors of this harmful condition to develop more effective prevention strategies. ${ }^{7}$ One predictor observed in some previous studies is the influence of parental drinking on the early onset of drug use. ${ }^{8}$ However, little has been reported on the association between parental drinking and future problems for adolescents.

Some studies have pointed out that early experimentation with alcohol and other drugs increases the risk of developing intense drinking episodes and drug-related problems, both in late adolescence and in adulthood. ${ }^{9}$ In addition, early experimentation with alcohol and other drugs is considered an important predictor of some mental disorders, cognitive impairment, and alcohol abuse and dependence. ${ }^{10}$

Available data suggest that polydrug use increases the odds of drug-related problems, such as violent episodes, drunkenness, unsafe driving, lower intellectual functioning, and psychiatric symptoms. ${ }^{11}$ There is strong evidence of the cooccurrence of alcohol and drug use problems and mental health problems among adolescents of both genders, although the direction of causality of this relationship is still unknown. ${ }^{12}$
How to cite this article: Almeida MC, Valente JY, Sanchez ZM. Predicting latent classes of drug-related problems among adolescents: secondary analysis of a cluster randomized controlled trial. Braz J Psychiatry. 2021;43:393-401. http://dx.doi.org/10.1590/15164446-2020-1075 
While many recent studies have pointed out that the early use of alcohol and other drugs increases the risk of subsequent drug-related problems, further longitudinal investigation is still needed to elucidate whether drug use leads to increased behavior problems or whether these problems contribute to the onset of drug use. ${ }^{13}$ Latent class analysis (LCA) is a mixed model that allows the categorization of different profiles of adolescents and the simultaneous analysis of drug use and drug-related problems.

The aims of this study are as follows: 1) to identify the latent patterns of drug-related problems among adolescents and the predictors of belonging to each risk group, including age, gender, socioeconomic status, past-year alcohol and drug use, participation in a drug-prevention program, parental drinking, and behavior problems; and 2) to investigate the possible effect of the aforementioned program on the combination of latent classes of drug use and problem behavior.

\section{Methods}

\section{Study design}

A randomized controlled trial was conducted among 6,391 students (3,130 boys; 3,261 girls) attending the 7th and 8th grades at 72 public schools in six Brazilian cities to evaluate the effects of \#Tamojunto, a schoolbased drug prevention program. This program is an adapted version of the European drug prevention program "Unplugged," and it was developed and implemented by the Brazilian Ministry of Health in 2014. Data were collected in February and November 2014 and in November 2015, generating a three-wave dataset (baseline/preintervention, 9 months after baseline, and 21 months after baseline). Detailed information on the study design is available elsewhere. ${ }^{14}$ For the current manuscript, we used data from the baseline and 21-month follow-up of the original trial.

\section{Sample}

Based on Lwanga \& Lemeshow's calculation ${ }^{15}$ of sample sizes for longitudinal studies, the sample size necessary for a power of $80 \%$, a significance level of $5 \%$, and a difference between groups of $1.5 \%$ points ( 5 vs. $3.5 \%$ ) in this study was determined to be 2,835 participants per group. Assuming that $50 \%$ of the participants would be lost to follow-up, the sample had to include 4,253 participants in each group. The parameters used were based on a previous pilot study and the expected results of the randomized controlled trial. Details of the study design and a flowchart of the sampling process are presented in Figure 1.

\section{Procedures and intervention}

The \#Tamojunto program was implemented in six Brazilian cities: São Paulo and São Bernardo do Campo, both in the state of São Paulo; the Brazilian Federal District (DF); Florianópolis and Tubarão, both in the state of Santa Catarina; SC; and Fortaleza, state of Ceará. Randomization was performed at the school level via an Excel macro [command RAND]. Seventy-two schools were randomly selected in proportion to the number of schools in each municipality (stratum): 31 schools in São Paulo, 10 schools in São Bernardo do Campo, four schools in the Federal District, eight schools in Florianópolis, eight schools in Tubarão, and 11 schools in Fortaleza. A second allocation step used a randomized list to determine whether each school would be assigned to the control or intervention group, maintaining a 1:1 allocation ratio per municipality.

The trial involved 6,391 students from the 7th and 8th grades of the selected schools. An independent team of researchers drawn from two universities performed an evaluation of the program. ${ }^{14}$

\section{Instruments and variables}

A translated and adapted Portuguese version of the anonymous self-report questionnaire developed by the European Drug Addiction Prevention Trial (EU-DAP) program was used to collect data for the present study. ${ }^{16}$ However, we replaced some questions with items from two widely used Brazilian instruments: the Brazilian Center for Information about Psychotropic Drugs (Centro Brasileiro de Informações Sobre Drogas Psicotrópicas CEBRID) ${ }^{17}$ and the National Survey of Student Health (Pesquisa Nacional de Saúde do Escolar - PENSE), used by the Brazilian Ministry of Health. ${ }^{18}$

The following variables were used: 1) baseline predictors: age; gender; socioeconomic class; randomized group (intervention/control); use (yes/no) of alcohol, tobacco, marijuana, and inhalants within the past year; parental drinking; and behavior problems; and 2) outcomes (21-month follow-up): past-year drug use and behavior problems.

Data regarding the students' socioeconomic class were collected using the Brazilian Association of Research Companies (Associação Brasileira de Empresas de Pesquisa ABEP) scale, ${ }^{19}$ which considers the educational attainment of each household members and the availability of some services and consumer goods. The scores range from 0 to 46 or comprise categories from A to E; higher scores indicate better economic standing, and socioeconomic classes are ranked from $A$ (highest) to $E$ (lowest). Parental drinking was assessed by asking the participants if their father or mother drinks occasionally (yes/no) and if she/he has episodes of drunkenness (yes/no). Behavior problems were evaluated using a set of questions from the original EUDAP instrument, ${ }^{16}$ which inquired whether the adolescents had experienced any of the following problems in the preceding 12 months: quarreling or arguments; fighting; accidents or injuries; loss of money or other valuable items; damage to material objects or clothing; parental relationship problems; problems in relationships with friends; skipping school; poor school performance; victimization by robbery; or hospitalization.

\section{Statistical analysis}

LCA was used to identify groups with similar patterns of drug use and problem behavior. The LCA model was 


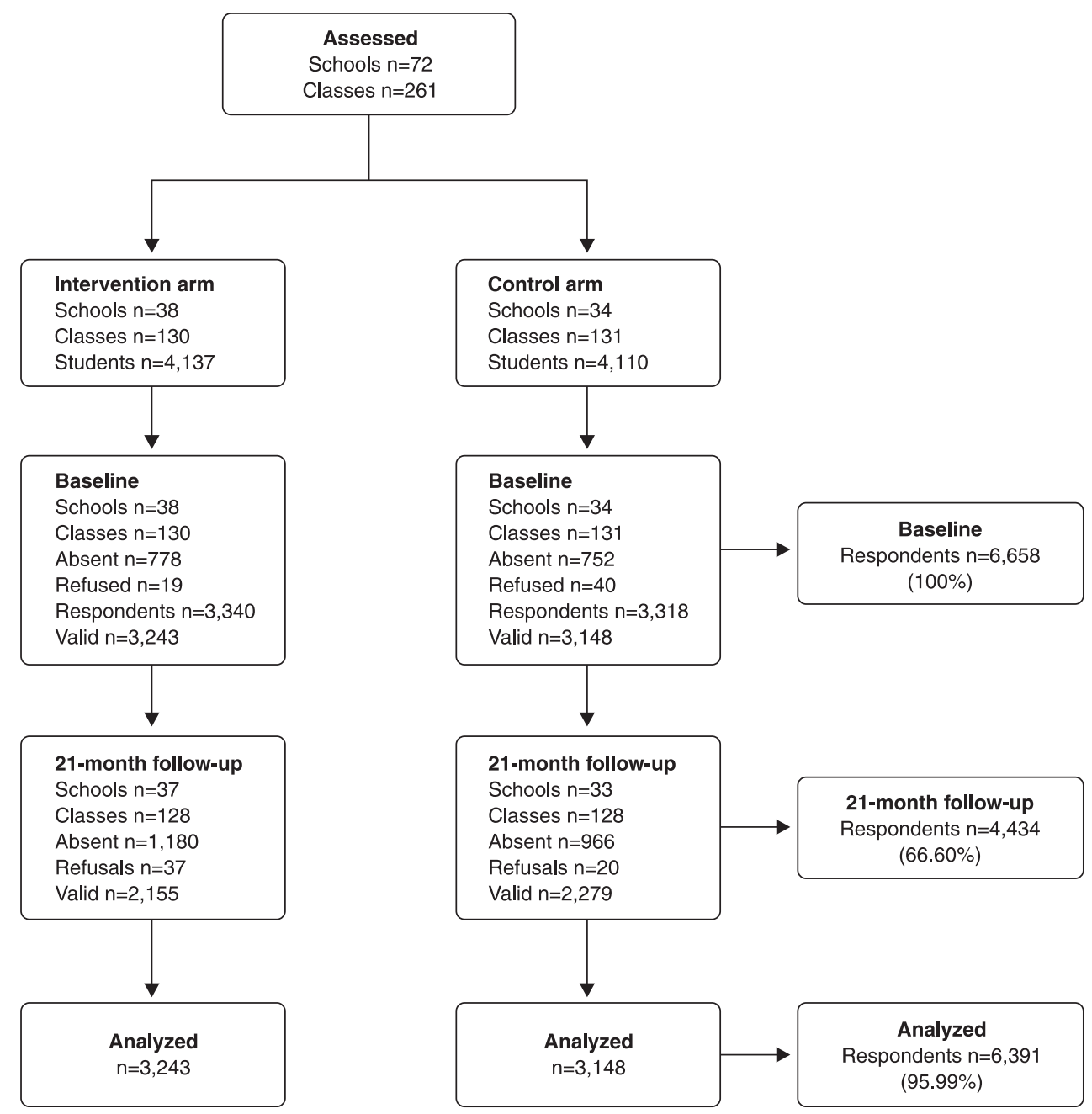

Figure 1 Flowchart of total sample data and sample data from baseline (February 2014) and 21-month follow-up (November 2015).

constructed with the variables related to drug use (alcohol, tobacco, marijuana, and inhalants) and problem behavior (11 items) in the past year at the 21-month follow-up assessment. The enumeration process extracted one to five classes. Due to the study's multilevel sampling, standard errors were corrected as described in Asparouhov's study, ${ }^{20}$ taking the school (second level) as the cluster indicator. The extraction of latent classes ceased when the addition of a new class yielded little additional information. The model was adjusted based on the goodness-of-fit criterion and took into consideration the parsimony and interpretability of the classes; that is, in addition to the statistical indices presented below, the model took into consideration whether each solution had a logical substantive interpretation. The goodness-of-fit statistics included the Akaike information criterion (AIC), the Bayesian information criterion (BIC), the sample-sizeadjusted Bayesian information criterion (SSABIC), and the Vuong-Lo-Mendell-Rubin (VLMR) test.

Because some of the data related to parental consumption, adolescent drug use, and problem behaviors at the 21-month follow-up were missing, we used a sequential imputation approach. ${ }^{21}$ Multiple imputations
(MI) were carried out using Bayes estimation of an unrestricted variance-covariance model, which was then used to impute the missing values. The sequential setting available in Mplus $^{21}$ version 7.4 was selected because there was a combination of continuous and categorical variables in our mediation models. The sequential setting uses a sequential regression method, also referred to as the chained equations algorithm, in line. Mls are random draws from the posterior distribution of the missing values. The following were used as variables in the unrestricted model: group, school, gender, age, ABEP classification, past-year drug use, and problem behavior at baseline. Five imputed datasets were generated.

To evaluate the reliability of the Ml analysis, we conducted a sensitivity analysis using another analytical approach to address the missing values and an approach using all available data to estimate the model through full information maximum likelihood (FIML), where each parameter is estimated directly without first filling in missing data values for each individual, assuming values are missing at random.

Subsequently, a logistic regression ${ }^{22}$ was performed using the Mplus R3STEP option of the AUXILIARY 
command, ${ }^{23}$ with the baseline covariant variables affecting the outcome at the 21-month follow-up (Figure 2). Mplus version 7.4 was used for all analyses. Because of the cluster structure (i.e., children nested in 72 schools), the standard errors and chi-square test of the model fit were adjusted for the children's nonindependence. To that aim, we used the COMPLEX option in Mplus, as proposed by Asparouhov, ${ }^{20}$ by specifying schools as a cluster variable. Inferential point estimates are given as adjusted odds ratios (aORs) with their respective 95\% confidence intervals $(95 \% \mathrm{Cl})$ and $\mathrm{p}$-values. The adopted level of significance was $5 \%$.

\section{Ethics statement}

The study was approved by the Universidade Federal de São Paulo research ethics committee (protocol 473498), and registered in the Brazilian Registry of Clinical Trials (Registro Brasileiro de Ensaios Clínicos - REBEC) under accession number RBR-4mnv5g. All school directors, teachers, and adolescents who agreed to participate voluntarily in the study signed a consent form.

\section{Results}

Table 1 presents the demographic characteristics of the students participating in the study $(n=6,391)$, which were drawn from the baseline dataset collected prior to the intervention. Most of the students were girls (51.21\%), with an average age of 12.62 years, who belonged to the middle-low socioeconomic class (53.98\%). Moreover, at baseline, the drug that was most commonly used by these students over the last year was alcohol (31.53\%), and the most prevalent behavior problem was being involved in quarrels or arguments (41.66\%). After 21 months, alcohol $(47.75 \%)$ continued to be the most prevalent drug used, and quarrels or arguments (41.66\%) continued to be the most prevalent problem behavior over the previous year. Approximately $27 \%$ of the participants reported skipping school and having parental relationship problems.

Five classes were defined, and the values of the information criteria are shown in Table S1, available as online-only supplementary material. The fit indices (lower $B I C, S S A B I C$, and $A I C)$ suggested that the two-class model was slightly superior to the other model. The model with two latent classes was chosen as the most parsimonious, as it presented values that were acceptable considering the goodness-of-fit criteria and interpretability from the perspective of the event.

The two classes that were distinguished were low drug use/low problems and high drug use/high problems. Adolescents classified as low drug use/low problems exhibited the lowest probabilities of having engaged in all four categories of drug use and in the 11 categories of problem behaviors. Those classified as high drug
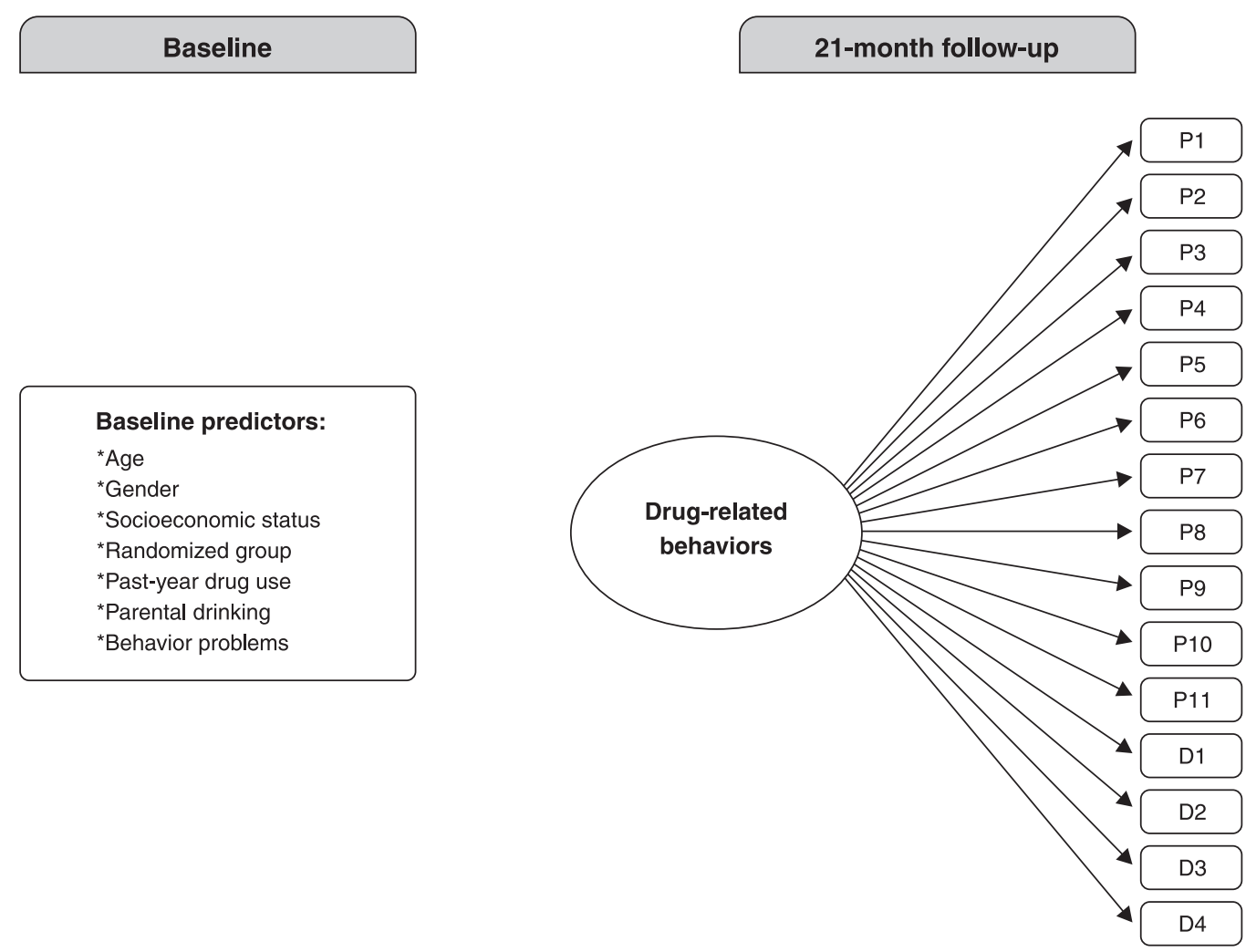

Figure 2 Latent class model of past-year drug-related behaviors with baseline predictors. P1 = Quarrel or argument; P2 = Fighting; P3 = Accident or injury; P4 = Loss of money or other valuable items; P5 = Damage to object or clothing; P6 = Parental relationship problems; P7 = Friends' relationship problems; P8 = Skipping school; P9 $=$ Poor school performance; $\mathrm{P} 10=$ Victimization by robbery; P11 = Hospitalization; D1 = Alcohol use; D2 = Cigarette use; D3 = Inhalant use; D4 = Cannabis use. 
Table 1 Outcomes and sociodemographic characteristics of students participating in the evaluation of the \#Tamojunto schoolbased program for drug use prevention $(n=6,391)$

\begin{tabular}{|c|c|c|c|}
\hline & \multirow{2}{*}{ Total $(n=6,391)$} & \multicolumn{2}{|c|}{ Group } \\
\hline & & Intervention arm $(n=3,148)$ & Control arm $(n=3,243)$ \\
\hline \multicolumn{4}{|l|}{ Gender } \\
\hline Male & $3,130(48.98)$ & $1,600(49.34)$ & $1,530(48.60)$ \\
\hline Female & $3,261(51.02)$ & $1,643(50.66)$ & $1,618(51.40)$ \\
\hline Age distribution $(n=6,391)$, mean $\pm S D$ & $12.62 \pm 0.82$ & $12.64 \pm 0.83)$ & $12.60 \pm 0.82$ \\
\hline \multicolumn{4}{|l|}{ Socioeconomic status* } \\
\hline A $(35-42)$ & $244(3.78)$ & $125(3.86)$ & $119(3.79)$ \\
\hline B (23-34) & $2,467(36.64)$ & $1,261(38.98)$ & $1,206(38.40)$ \\
\hline C (14-22) & $3,343(53.98)$ & $1,704(52.67)$ & $1,639(52.18)$ \\
\hline D/E (0-13) & $322(5.60)$ & $145(4.48)$ & $177(5.64)$ \\
\hline \multicolumn{4}{|l|}{ Baseline past-year drug use } \\
\hline Alcohol & $2,015(31.53)$ & $1,014(31.30)$ & $1,001(31.80)$ \\
\hline Tobacco & $243(3.80)$ & $128(3.90)$ & $115(3.70)$ \\
\hline Inhalants & $525(8.21)$ & $271(8.40)$ & $254(8.10)$ \\
\hline Cannabis & $156(2.44)$ & $83(2.60)$ & $73(2.30)$ \\
\hline \multicolumn{4}{|l|}{ Baseline past-year problem behavior } \\
\hline Quarrel or argument & $1,631(27.55)$ & $830(27.71)$ & $801(27.38)$ \\
\hline Fighting & $952(16.03)$ & 477 (15.87) & $475(16.18)$ \\
\hline Accident or injury & $587(9.93)$ & $300(10.01)$ & $287(9.86)$ \\
\hline Loss of money or others & $548(9.27)$ & $277^{\prime}(9.25)$ & 271 (9.29) \\
\hline Damage to object or clothing & $429(7.26)$ & $224(7.50)$ & $205(7.01)$ \\
\hline Parental relationship problems & $932(15.79)$ & $448(14.98)$ & 484 (16.62) \\
\hline Friends' relationship problems & $888(15.05)$ & $455(15.26)$ & $433(14.83)$ \\
\hline Skipping school & $786(13.32)$ & $392(13.14)$ & $394(13.50)$ \\
\hline Poor school performance & $493(8.35)$ & $262(8.77)^{\prime}$ & $231(7.91)$ \\
\hline Victimization by robbery & $330(5.58)$ & $164(5.49)$ & $166(5.67)$ \\
\hline Hospitalization & $392(6.63)$ & $175(5.86)$ & $217(7.41)$ \\
\hline \multicolumn{4}{|l|}{ Baseline parental alcohol use } \\
\hline Maternal alcohol use & $1,308(20.86)$ & $619(19.56)$ & $689(22.20)$ \\
\hline Maternal drunkenness & $150(2.39)$ & $77(2.43)$ & $73(2.35)$ \\
\hline Paternal alcohol use & $1,908(30.44)$ & $931(29.42)$ & 977 (31.48) \\
\hline Paternal drunkenness & $598(9.54)$ & $279(8.82)$ & $319(10.28)$ \\
\hline \multicolumn{4}{|l|}{ Follow-up past-year drug use } \\
\hline Alcohol & $1,731(47.75)$ & $882(49.80)$ & $849(45.79)$ \\
\hline Tobacco & $252(6.99)$ & $128(3.99)$ & $115(3.69)$ \\
\hline Inhalants & $377(10.45)$ & $271(8.45)$ & $254(8.14)$ \\
\hline Cannabis & $276(7.67)$ & $143(8.15)$ & $133(7.20)$ \\
\hline \multicolumn{4}{|l|}{ Follow-up past-year problem behavior } \\
\hline Quarrel or argument & $1,482(41.66)$ & $746(43.00)$ & $736(40.40)$ \\
\hline Fighting & $778(21.85)$ & $379(21.83)$ & $399(21.88)$ \\
\hline Accident or injury & $390(11.00)$ & $183(10.58)$ & $207(11.40)$ \\
\hline Loss of money or others & 474 (13.33) & $237(13.68)$ & $237(13.00)$ \\
\hline Damage to object or clothing & $382(10.78)$ & $179(10.38)$ & $203(11.16)$ \\
\hline Parental relationship problems & $931(26.17)$ & $482(27.80)$ & 449 (24.62) \\
\hline Friends' relationship problems & $835(23.52)$ & $432(25.00)$ & $403(22.12)$ \\
\hline Skipping school & $970(27.30)$ & 475 (27.39) & $495(27.21)$ \\
\hline Poor school performance & $676(19.05)$ & $324(18.74)$ & $352(19.34)$ \\
\hline Victimization by robbery & $296(8.32)$ & $134(7.74)$ & $162(8.87)$ \\
\hline Hospitalization & $273(7.68)$ & $121(6.98)$ & $152(8.34)$ \\
\hline
\end{tabular}

Data presented as $\mathrm{n}(\%)$, unless otherwise specified.

$\mathrm{SD}=$ standard deviation.

* According to the Brazilian Association of Research Companies (Associação Brasileira de Empresas de Pesquisa - ABEP). ${ }^{19}$

use/high problems exhibited the highest probabilities of having engaged in all four categories of drug use and in the 11 categories of problem behaviors. The high drug use/high problems class was the smallest (40/36.71\%), and the low drug use/low problems class was the largest $(60 / 63.28 \%)$, as seen in Figure 3 , which shows the weighted probabilities consecutively, without and with imputed data.

Problem behaviors were assessed by asking whether the students had experienced any of the following problems in the preceding 12 months: (P1) quarrel or argument; (P2) fighting; (P3) accident or injury; (P4) loss of 
Latent classes with full-information maximum likelihood

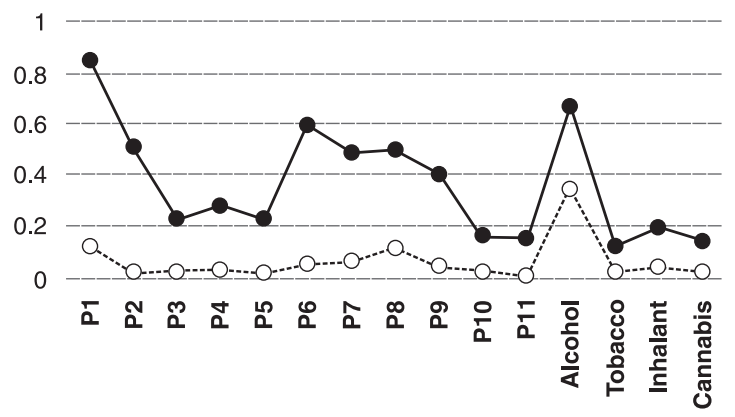

- High drug use/High problems ( $n=1445 / 40 \%)$

....-.... Low drug use/Low problems $(n=2190 / 60 \%)$
Latent classes with multiple imputation

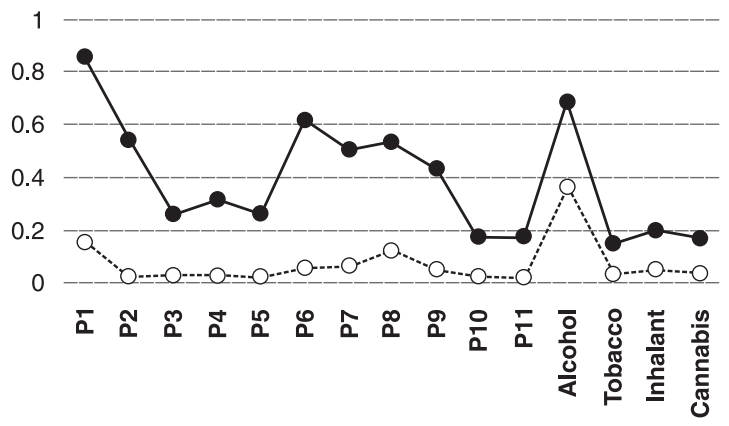

$\longrightarrow$ High drug use/High problems ( $n=2347 / 72 \%)$

...-.... Low drug use/Low problems $(n=4004 / 63,28 \%)$

Figure 3 Weighted probabilities of occurrence of problem behaviors and drug use during the past year according to the twolatent-class model, with a full-information maximum likelihood approach or multiple imputations, among adolescents participating in the 21-month follow-up of a study of a school-based drug-use prevention program $(n=3,635 / 6,391)$.

money or other valuable items; (P5): damage to object or clothing; (P6) parental relationship problems; (P7) friends relationship problems; (P8) skipping school; (P9) poor school performance; (P10) victimization by robbery; and (P11) hospitalization.

Table 2 shows the results of the integrative models, which were logistic regression models (univariate and multivariate) using the latent classes as the outcomes. Regardless of the methodological approach used to deal with missing data (MI or FIML), the majority of the points estimated and the confidence intervals were similar, indicating stability of the estimations and findings. Girls were more likely to belong to the high drug use/high problems class than to the low drug use/low problems class $(\mathrm{aOR}=1.69,95 \% \mathrm{Cl}=1.09 ; 2.62$ and $\mathrm{aOR}=2.22$, $95 \% \mathrm{Cl}=[1.09 ; 2.62]$, MI and FIML, respectively). Adolescents who reported using alcohol at baseline were more likely to be in the high drug use/high problems class than in the low drug use/low problems class $(\mathrm{aOR}=1.71$, $95 \% \mathrm{Cl}=1.03 ; 2.85$ and $\mathrm{aOR}=1.59,95 \% \mathrm{Cl}=1.00 ; 2.50$, $\mathrm{MI}$ and FIML, respectively). Adolescents who reported problem behaviors at baseline were also more likely to be in the high drug use/high problems class than in the low drug use/low problems class $(\mathrm{aOR}=16.05,95 \% \mathrm{Cl}=$ $10.27 ; 25.10$ and $\mathrm{aOR}=57.0038 .14 ; 95 \% \mathrm{Cl}=85.18, \mathrm{Ml}$ and FIML, respectively).

To better describe the gender difference, the distribution of problem behaviors in the preceding year according to gender is detailed in Table S2, available as online-only supplementary material. It is worth noting that, except for accidents and injuries, all other problem behaviors that showed differences between genders were more prevalent among girls.

Concerning parental alcohol use, students who reported at least one episode of maternal drunkenness showed a trend to be more likely to belong to the high drug use/high problems class than to the low drug use/ low problems class $(\mathrm{aOR}=2.87,95 \% \mathrm{Cl}=0.99 ; 8.32$ and $\mathrm{aOR}=4.78,95 \% \mathrm{Cl}=1.33 ; 17.20, \mathrm{Ml}$ and $\mathrm{FIML}$, respectively).

\section{Discussion}

This longitudinal study used LCA to evaluate latent classes of drug-related problems among Brazilian adolescents. We found that two distinct groups provided the best explanation for the patterns of drug use and problem behaviors: high drug use/high problems and low drug use/low problems. Female gender, episodes of maternal drunkenness, and earlier age at initiation of alcohol use and problem behavior were identified as possible predictors of belonging to the high drug use/high problems class.

The two different classes related to drug use and behavior problems that we found are in line with recent literature indicating a strong association between adolescent drug use and increased occurrence of behavioral problems, including school functioning, ${ }^{24}$ aggression and delinquency, ${ }^{25}$ and physical violence. ${ }^{26}$ The greater the use of drugs, the greater the number of problems reported.

The main predictors of being in the high drug use/high problems class were earlier alcohol use initiation and problem behavior, which suggests that early attention should be directed to these adolescents, since time tends to accentuate behavior problems and alcohol use and these issues do not resolve on their own. This finding is consistent with other studies, which also found that having a behavior problem is predictive of later engagement in behavior problems. ${ }^{27}$ That initiation of alcohol use at an earlier age was a predictor for the high drug use/ high problems class is also in line with previous studies, confirming the strong evidence that early alcohol initiation is a risk factor for several social and public health issues, ${ }^{28}$ including academic difficulties, employment problems, substance use, and delinquent and violent behaviors. ${ }^{9}$ These findings highlight the fact that delaying the onset of alcohol use may help reduce the risk of drug problems for most adolescents.

Although well-established data indicate that men drink more alcohol and have more alcohol use problems than 


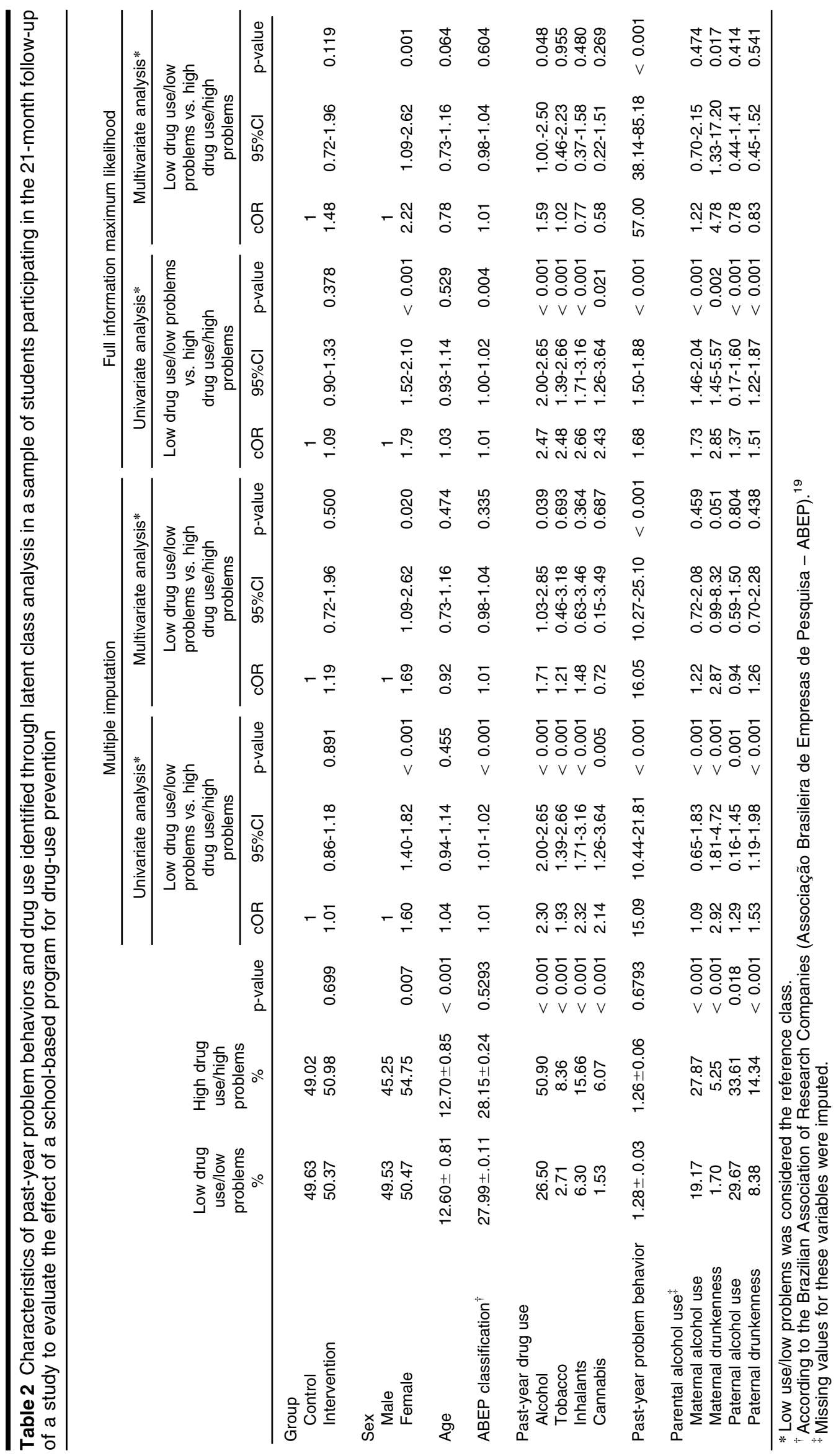


women, ${ }^{29}$ previous studies have highlighted that these differences are greater than the differences between male and female adolescents. ${ }^{30}$ Additionally, an increase in rates of alcohol and other drug use and drug-related problems by girls has been observed recently, due to general changes in women's role in society and an increase in more permissive attitudes toward women's drinking. ${ }^{31}$ In Brazil, there is even recent evidence from a national survey pointing out that girls are drinking more than boys. ${ }^{5}$ Our finding of female gender as a predictor of drug-related problems may be explained by these changes in the current pattern of adolescent alcohol use according to gender, and by the fact that girls are biologically more susceptible to the effects of drugs. ${ }^{32,33}$ These gender differences may justify why alcohol use seems to have more harmful consequences in girls. ${ }^{30}$ This trend suggests that public health efforts must consider the narrowing of gender differences and a potential shift in social attitudes and norms regarding female gender and drug use.

One aspect that has recently received considerable attention is parental drinking as a predictor of drug-related problems. Our findings indicate (as a marginal effect, with $p=0.051$ ) that episodes of maternal drunkenness may lead to greater drug use/problems. Our results are in accordance with other studies that have indicated that maternal drunkenness is an important predictor of adolescent drug use ${ }^{34}$ and alcohol misuse. ${ }^{35}$ This effect of episodes of maternal drunkenness on adolescents' drugrelated problems may be due to the well-known role of maternal influences on adolescent development, ${ }^{36}$ as maternal alcohol abuse may serve as a model for adolescent behavior by promoting a perception of low levels of risk associated with drug use. ${ }^{37}$ Another possible explanation is that exposure to episodes of maternal drunkenness is hazardous to adolescents' emotional development, leading to drug-related problems. ${ }^{38}$ In addition, mothers who present episodes of drunkenness may have greater access to alcohol and may allow their children to drink alcohol earlier; these two factors are highly associated with alcohol-related problems. ${ }^{39}$ This finding highlights the importance of public health prevention approaches that target parental alcohol abuse and educate parents to be more aware of their role in preventing drug-related problems.

Some limitations of this study should be considered. First, we only collected self-reported measures from the adolescents, and these may be subject to underreporting of drug use or misinterpretation of the described problems. Moreover, as expected for longitudinal studies, we had some data loss over time. Therefore, we utilized the imputation process as a recommended solution for this problem. ${ }^{40}$

Finally, the findings of this study allow us to conclude that drug use and behavior problems tend to be grouped together in two latent classes (high/low). Female gender, exposure to maternal drunkenness, and earlier alcohol use initiation and problem behavior play important roles in the prediction of drug-related problems during early adolescence. These findings suggest that childhood intervention, based on evidence-based programs, should be initiated before 7 th grade. ${ }^{41}$ Some useful options to identify adolescents at risk are early screening for behavioral problems and screening and brief intervention for maternal drunkenness.

\section{Acknowledgements}

This study was funded by the Brazilian Ministry of Health (TED 89-2014). The authors thank the technical team at the Ministry of Health, the State and Municipal Departments of Health and Education involved, and all the teachers and adolescents who participated in the study. This study is part of the Center for Research and Innovation in Prevention of Mental Disorders and Drug Use, funded by the Brazilian Ministry of Health. MCA receives a $\mathrm{PhD}$ scholarship from Conselho Nacional de Desenvolvimento Científico e Tecnológico (CNPq). JYV receives a $\mathrm{PhD}$ scholarship from Fundação de Amparo à Pesquisa do Estado de São Paulo (FAPESP).

\section{Disclosure}

The authors report no conflicts of interest.

\section{References}

1 Dolto F. A causa dos adolescentes. São Paulo: Idéias \& Letras; 2015.

2 Abramovitch S, Moreira M. Transtornos psiquiátricos. In: Brasil, Ministério da saúde. Saúde do adolescente: competências e habilidades. Brasília: Ministério da Saúde; 2008. p. 136-44.

3 Braga LDL, Dell'Aglio DD. Suicídio na adolescência: fatores de risco, depressão e gênero. Context Clinic. 2013;6:2-14.

4 Esser MB, Clayton H, Demissie Z, Kanny D, Brewer RD. Current and binge drinking among high school students -- United States, 19912015. MMWR Morb Mortal Wkly Rep. 2017;66:474-8.

5 Brasil, Ministério da Saúde, Instituto Brasileiro de Geografia e Estatística (IBGE). Pesquisa nacional de saúde do escolar 2015 [Internet]. 2016 [cited 2020 Aug 31]. biblioteca.ibge.gov.br/visualizacao/livros/ liv97870.pdf

6 Gutierrez A, Sher L. Alcohol and drug use among adolescents: an educational overview. Int J Adolesc Med Health. 2015;27:207-12.

7 Degenhardt L, Stockings E, Patton G, Hall WD, Lynskey M. The increasing global health priority of substance use in young people. Lancet Psychiatry. 2016;3:251-64.

8 Rossow I, Keating P, Felix L, McCambridge J. Does parental drinking influence children's drinking? A systematic review of prospective cohort studies. Addiction. 2016;111:204-17.

9 Kim MJ, Mason WA, Herrenkohl TI, Catalano Rf, Toumbourou JW, Hemphill SA. Influence of early onset of alcohol use on the development of adolescent alcohol problems: a longitudinal binational study. Prev Sci. 2017;18:1-11.

10 Liang W, Chikritzhs T. Age at first use of alcohol predicts the risk of heavy alcohol use in early adulthood: a longitudinal study in the United States. Int J Drug Policy. 2015;26:131-4.

11 Lipperman-Kreda S, Gruenewald PJ, Grube JW, Bersamin M. Adolescents, alcohol, and marijuana: context characteristics and problems associated with simultaneous use. Drug Alcohol Depend. 2017;179:55-60.

12 Skogen JC, Sivertsen B, Lundervold AJ, Stormark KM, Jakobsen R, Hysing M. Alcohol and drug use among adolescents: and the cooccurrence of mental health problems. Ung@ @ordaland, a population-based study. BMJ Open. 2014;4:e005357.

13 Grigsby TJ, Forster M, Unger JB, Sussman S. Predictors of alcoholrelated negative consequences in adolescents: a systematic review of the literature and implications for future research. J Adolesc. 2016; 48:18-35.

14 Sanchez ZM, Valente JY, Sanudo A, Pereira AP, Cruz JI, Schneider $D$, et al. The \#Tamojunto drug prevention program in Brazilian schools: a randomized controlled trial. Prev Sci. 2017;18:772-82. 
15 Lwanga SK, Lemeshow S. Sample size determination in health studies: a practicle manual. Geneva: World Health Organization; 1991.

16 Faggiano F, Vigna-Taglianti F, Burkhart G, Bohrn K, Cuomo L, Gregori D, et al. The effectiveness of a school-based substance abuse prevention program: 18-Month follow-up of the EU-Dap cluster randomized controlled trial. Drug Alcohol Depend. 2010;108:56-64.

17 Carlini EL de A, Noto AR, Sanchez Z van der M, et al. VI Levantamento nacional sobre o consumo de drogas psicotrópicas entre estudantes do ensino fundamental e médio das redes pública e privada de ensino nas 27 capitais brasileiras. Volume 1. Brasília: Secretaria Nacional de Políticas sobre Drogas (SENAD); 2010.

18 Brasil, Ministério da Saúde, Instituto Brasileiro de Geografia e Estatística (IBGE). Pesquisa nacional de saúde do escolar 2012 [Internet]. 2013 [cited 2020 Aug 31]. biblioteca.ibge.gov.br/visualizacao/ livros/liv64436.pdf

19 Associação Brasileira de Empresas de Pesquisa (ABEP). Critério de classificação econômica do Brasil [Internet] [cited 2017 Feb 15]. www.abep.org/criterio-brasil

20 Asparouhov T. General multi-level modeling with sampling weights. Commun Stat Theory Methods. 2006;35:439-60.

21 Muthén LK, Muthén BO. Mplus statistical analysis with latent variables user's guide. 6th ed. Los Angeles: Muthén \& Muthén; 2010.

22 Hosmer DW, Lemeshow S, Sturdivant RX. Applied logistic regression. 3rd edition. New York: John Wiley \& Sons; 2013.

23 Asparouhov T, Muthén B. Auxiliary variables in mixture modeling: threestep approaches using Mplus. Struct Equ Modeling. 2014;21:329-41.

24 Heradstveit O, Skogen JC, Hetland J, Hysing M. Alcohol and illicit drug use are important factors for school-related problems among adolescents. Front Psychol. 2017;8:1023.

25 Farrell AD, Kung EM, White KS, Valois RF. The structure of selfreported aggression, drug use, and delinquent behaviors during early adolescence. J Clin Child Psychol. 2000;29:282-92.

26 de Carvalho AP, da Silva TC, Valença PA, Ferreira Santos CF, Colares V, de Menezes VA. Alcohol consumption and physical violence among adolescents: which is the predictor? Cien Saude Colet. 2017;22:4013-20.

27 Rowland B, Jonkman H, Steketee M, Solomon RJ, Solomon S, Toumbourou JW. A cross-national comparison of the development of adolescent problem behavior: a 1-year longitudinal study in India, the Netherlands, the USA, and Australia. Prev Sci. 2019 Apr 6. doi: 10.1007/s11121-019-01007-3. Online ahead of print

28 Kuntsche E, van der Vorst $\mathrm{H}$, Engels $\mathrm{R}$. The earlier the more? Differences in the links between age at first drink and adolescent alcohol use and related problems according to quality of parent-child relationships. J Stud Alcohol Drugs. 2009;70:346-54.
29 Mancha BE, Rojas VC, Latimer WW. Alcohol use, alcohol problems, and problem behavior engagement among students at two schools in northern Mexico. Alcohol. 2012;46:695-701.

30 Schulte MT, Ramo D, Brown SA. Gender differences in factors influencing alcohol use and drinking progression among adolescents. Clin Psychol Rev. 2009;29:535-47.

31 Wolle CC, Sanches M, Zilberman ML, Caetano R, Zaleski M, Laranjeira RR, et al. Differences in drinking patterns between men and women in Brazil. Braz J Psychiatry. 2011;33:367-73.

32 Choi HJ, Elmquist J, Shorey RC, Rothman EF, Stuart GL, Temple JR Stability of alcohol use and teen dating violence for female youth: a latent transition analysis. Drug Alcohol Rev. 2017;36:80-7.

33 Medina KL, McQueeny T, Nagel BJ, Hanson KL, Schweinsburg AD, Tapert SF. Prefrontal cortex volumes in adolescents with alcohol use disorders: unique gender effects. Alcohol Clin Exp Res. 2008;32: 386-94.

34 Valente JY, Cogo-Moreira H, Sanchez ZM. Predicting latent classes of drug use among adolescents through parental alcohol use and parental style: a longitudinal study. Soc Psychiatry Psychiatr Epidemiol. 2019;54:455-67.

35 Yap MB, Cheong TW, Zaravinos-Tsakos F, Lubman DI, Jorm AF. Modifiable parenting factors associated with adolescent alcohol misuse: a systematic review and meta-analysis of longitudinal studies. Addiction. 2017;112:1142-62.

36 King SM, Keyes M, Malone SM, Elkins I, Legrand LN, Iacono WG, et al. Parental alcohol dependence and the transmission of adolescent behavioral disinhibition: a study of adoptive and non-adoptive families. Addiction. 2009;104:578-86.

37 Patrick ME, Maggs JL, Greene KM, Morgan NR, Schulenberg JE. The link between mother and adolescent substance use: inter-generational findings from the British cohort study. Longit Life Course Stud. 2014;5:56-63.

38 Knudsen AK, Ystrom E, Skogen JC, Torgersen L. Maternal heavy alcohol use and toddler behavior problems: a fixed effects regression analysis. Eur Child Adolesc Psychiatry. 2015;24:1269-77.

39 Mattick RP, Clare PJ, Aiken A, Wadolowski M, Hutchinson D, Najman $\mathrm{J}$, et al. Association of parental supply of alcohol with adolescent drinking, alcohol-related harms, and alcohol use disorder symptoms: a prospective cohort study. Lancet Public Health. 2018;3:e64-71.

40 Dong Y, Peng CY. Principled missing data methods for researchers. Springerplus. 2013;2:222.

41 United Nations Office on Drugs and Crime (UNODC). International standards on drug use prevention [Internet]. 2015 [cited 2017 Feb 15]. www.unodc.org/documents/prevention/UNODC_2013_2015_ international_standards_on_drug_use_prevention_E.pdf 